\title{
Descriptions of two new species of Sphenorhina (Hemiptera, Cercopidae, Tomaspidinae) from the Neotropical region
}

\author{
Andressa Paladini ${ }^{1} \&$ Gervásio Silva Carvalho²
}

${ }^{1}$ Universidade Federal do Paraná, Setor de Ciências Biológicas, Departamento de Zoologia, Programa de Pós-graduação em Entomologia, Caixa Postal 19020, 81531-980 Curitiba - PR, Brazil. andri_bio@yahoo.com.br

${ }^{2}$ Laboratório de Entomologia, Programa de Pós-Graduação em Zoologia, Faculdade de Biociências, Pontifícia Universidade Católica do Rio Grande do Sul, Av. Ipiranga, 6681, Porto Alegre/RS, 90619-900, Brazil. gervasio@pucrs.br

\begin{abstract}
Description of two new species of Sphenorhina (Hemiptera, Cercopidae, Tomaspidinae) from the Neotropical region. Two new species of Sphenorhina Amyot \& Serville, S. pseudoboliviana sp. nov. from Bolivia and S. plata sp. nov. from Argentina are described and illustrated.
\end{abstract}

KEYWORDS. Auchenorrhyncha; spittlebug; taxonomy

Cercopoidea form the largest group of xylem-sap sucking insects. The insects belonging to the largest family, Cercopidae, are popularly known as spittlebugs. They are easily characterized by the presence of one or two lateral spines and an apical crown of spines on the hind tibia. Most of the species have the tegmina with bright colors.

Sphenorhina was established by Amyot \& Serville (1843) without designation of a type-species. It is a Neotropical genus that currently includes 60 valid species (Carvalho \& Webb 2005), most of them previously included in Tomaspis and Monecphora. In this paper we add two new species from Bolivia and Argentina to the genus.

\section{MATERIAL AND METHODS}

The specimens studied herein are deposited in the following institutions: Museo Argentino de Ciencias Naturales "Bernardino Rivadavia", Buenos Aires, Argentina (MACN); Museu de Ciências e Tecnologia, Pontifícia Universidade Católica do Rio Grande do Sul, Porto Alegre, Brazil (MCTP); and Departamento de Zoologia, Universidade Federal do Paraná, Curitiba, Brazil (DZUP).

Morphological terminology follows Fennah (1968). Measurements were taken with an optical micrometer. Photographs were obtained with a Leica DFC-550 digital camera attached to a Leica MZ16 stereoscopic microscope. Individual digital images were captured with software IM50 (Image Manager; Leica Microsystems Imaging Solutions Ltd, Cambridge, UK) and electronically assembled into a single panfocal image with the Auto-Montage Syncroscopy from Taxonline (Rede Paranaense de Coleções). Genitalia structures were drawn with a camera lucida and the final illustrations were digitally vectorized in CorelDraw version X5.

\section{TAXONOMY}

\section{Sphenorhina Amyot \& Serville, 1843}

Sphenorhina Amyot \& Serville, 1843: 562; Metcalf, 1961: 185; Fennah, 1968: 179.

Type species: Cicada rubra Linné, 1758: 438, by subsequent designation (Blanchard, 1848: 747).

Phytozamia Fennah, 1949: 610; synonymized by Metcalf, 1961: 185.

Type species: Cicada rubra Linné, 1758: 438.

Species of the genus can be distinguished from other Neotropical cercopids by the following characters: postclypeus narrow, not strongly compressed and very swollen, apex right or acute angled in profile; third antennal segment with short and rounded basal body bearing a single subapical arista commonly long, occasionally up to 0.66 length of flagellum; pygofer with a lateral process between anal tube and subgenital plates, these slender, length up to four times basal width; aedeagus slender, upright, covered with small tooth-like spines.

\section{Sphenorhina pseudoboliviana sp. nov.}

(Figs. 1-2; 5-9)

Average Measurements (mm). Males (4 specimens): overall length, 11.33; tegmina length, 8.75. Females (2 specimens): overall length, 11.6; tegmina length, 10.1 .

Holotype. Head black; compound eyes brownish, rounded, arranged transversely; vertex smooth and rectangular with a slightly marked median carina; ocelli brownish, closer to each other than to the eyes; tylus black, smooth and quadrangular, with a strongly marked median carina; antennae black, pedicel setose, basal body of the flagellum conic with an arista longer than pedicel; postclypeus black, inflated, angulated in profile, longitudinal carina strongly marked and prominent and 

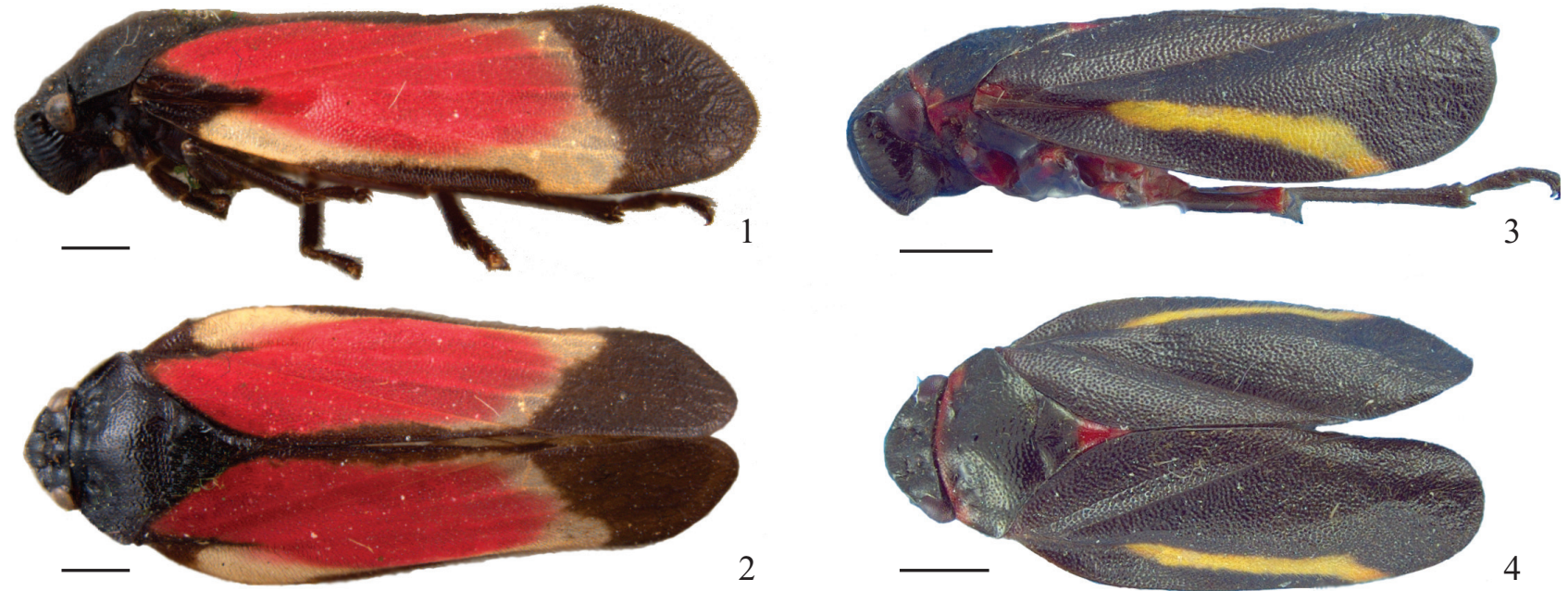

Figs. 1-4. 1-2. Sphenorhina pseudoboliviana sp. nov. 1. Paratype (MCTP-29444), lateral view. 2. Paratype (MCTP-29444), dorsal view. 3-4. Sphenorhina plata sp. nov. 3. Paratype (DZUP-male), lateral view. 4. Paratype, dorsal view (DZUP-male). Bars $=1 \mathrm{~mm}$.
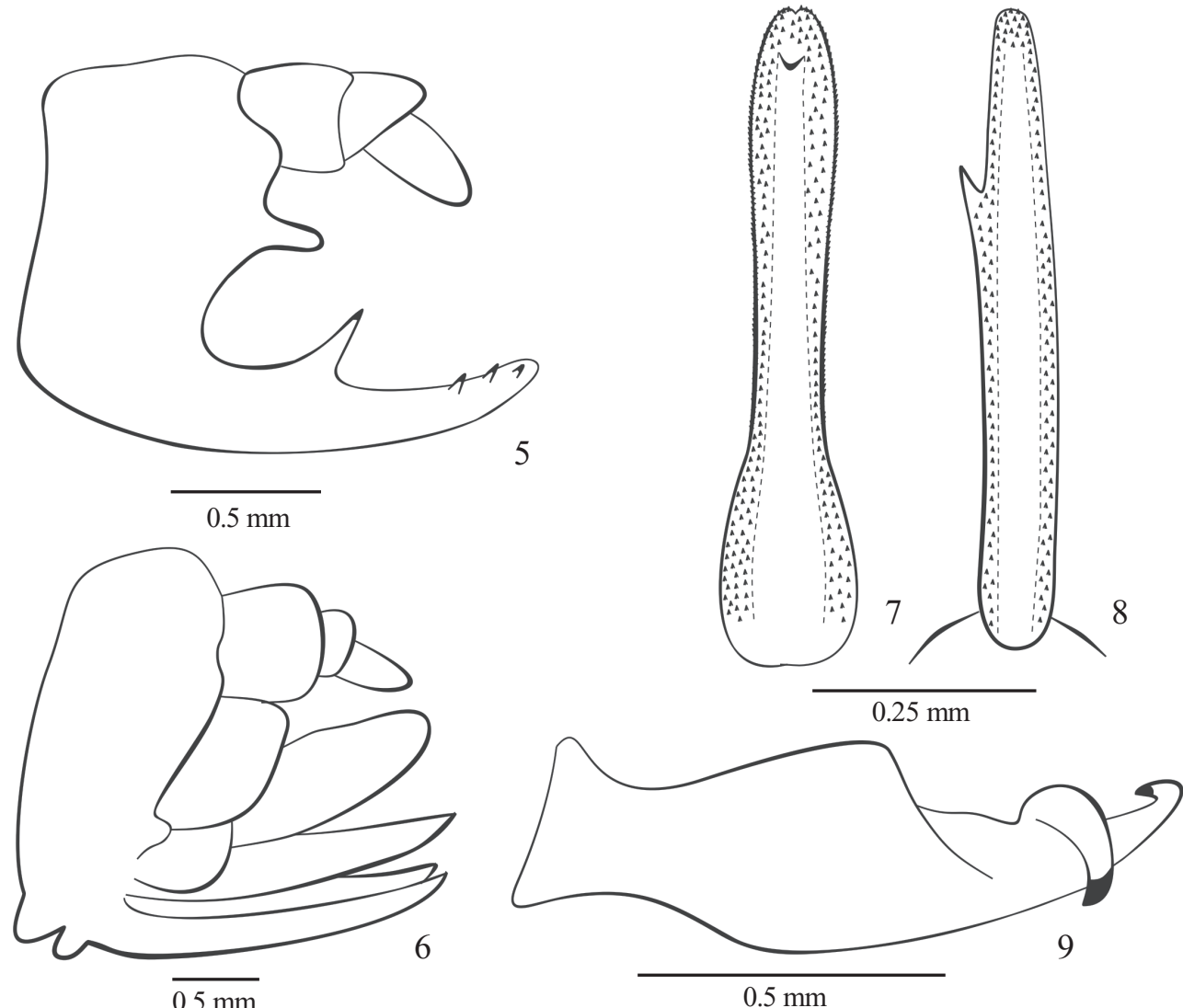

Figs. 5-9. Sphenorhina pseudoboliviana sp. nov. 5. Male pygofer, lateral view (MACN-8077). 6. Female pygofer, lateral view (MCTP-29443). 7. Aedeagus, dorsal view (MACN-8077). 8. Aedeagus, lateral view (MACN-8077). 9. Paramere, lateral view (MACN-8077).

lateral grooves strongly marked. Prothorax, mesothorax and metathorax black; pronotum black, finely punctured, hexagonal with an apparent median carina; anterior margin straight, lateral-anterior margins straight, lateral posterior margin slightly sinuous, posterior margin almost straight; scutellum black, with a central concavity with slightly marked transversal grooves; tegmina with humeral area, median portion of the dorsal margin, apical third and anal margin until the apex of the clavus, black, central area red and a yellowish stripe beginning in the basal third of the costal margin extending until the apical third narrowing between the black and the red maculae; apical reticulation well developed. Hind 
wing with brown venation, vein $\mathrm{Cu}_{1}$ not thickened at the base; legs black, metathoracic tibia with two lateral spines: the basal one smaller than those located in the apical crown of the tibiae and the apical one equal, basitarsus with three rows of apical spines covered with sparse setae, subungueal process present and similar to the shape of a claw.

Male genitalia. Pygofer black with one finger-like process covered with small tooth-like spines between the anal tube and the subgenital plates, subgenital plates long and slender with one long and acute process in the dorsal margin, three small spines situated in the dorsal margin near the apex (Fig. 5), parameres with dorsal process developed, apex long with a sclerotized apical spine directed backwards and a large subapical spine directed downward (Fig. 9); aedeagus cylindrical, covered with a large number of minute tooth-like spines, with one median spine in the ventral face directed upward, and a subapical gonopore (Figs. 7-8).

Female genitalia. First valve of the ovipositor long and slender with the dorsal margin smooth and two basal processes rounded and directed backward; second valve of the ovipositor long and slender without teeth on the dorsal margin, third valve short and wide with long hairs on the ventral surface (Fig. 6).

Type material. Holotype male: BOLIVIA: La Paz, Chulumani Sur-Yungas, -.I.1948 Bridarolli leg. (MACN-8077).
Paratypes: 1 male and 1 female, same data as holotype (MCTP29444 and 29443 - ex MACN-8076 and 8081); 2 males and 1 female, same data as holotype (MACN-8078-8080-8083).

Remarks. This species resembles Sphenorhina boliviana (Jacobi, 1908) in the shape of the male genitalia but the color pattern of the tegmina is totally different having red tegmina with a narrow longitudinal stripe in the middle, humeral angle, costal margin, and the apex, black.

Etymology. The species name refers to the similarity of S. pseudoboliviana to $S$. boliviana.

\section{Sphenorhina plata sp. nov.}

(Figs. 3-4; 10-14)

Average Measurements (mm). Males ( 5 specimens): overall length, 7.92; tegmina length, 6.3. Females (2 specimens): overall length, 7.1; tegmina length, 5.65.

Holotype. Head black; compound eyes reddish, rounded, arranged transversely; vertex smooth, rectangular, without a median carina; ocelli reddish closer to each other than to eyes; tylus black rectangular without a median carina; antennae black, pedicel sparsely setose, basal body of flagellum subcylindrical with an arista longer than pedicel; postclypeus swollen with a longitudinal carina strongly marked and prominent, angulated profile, lateral grooves strongly marked. Pro-
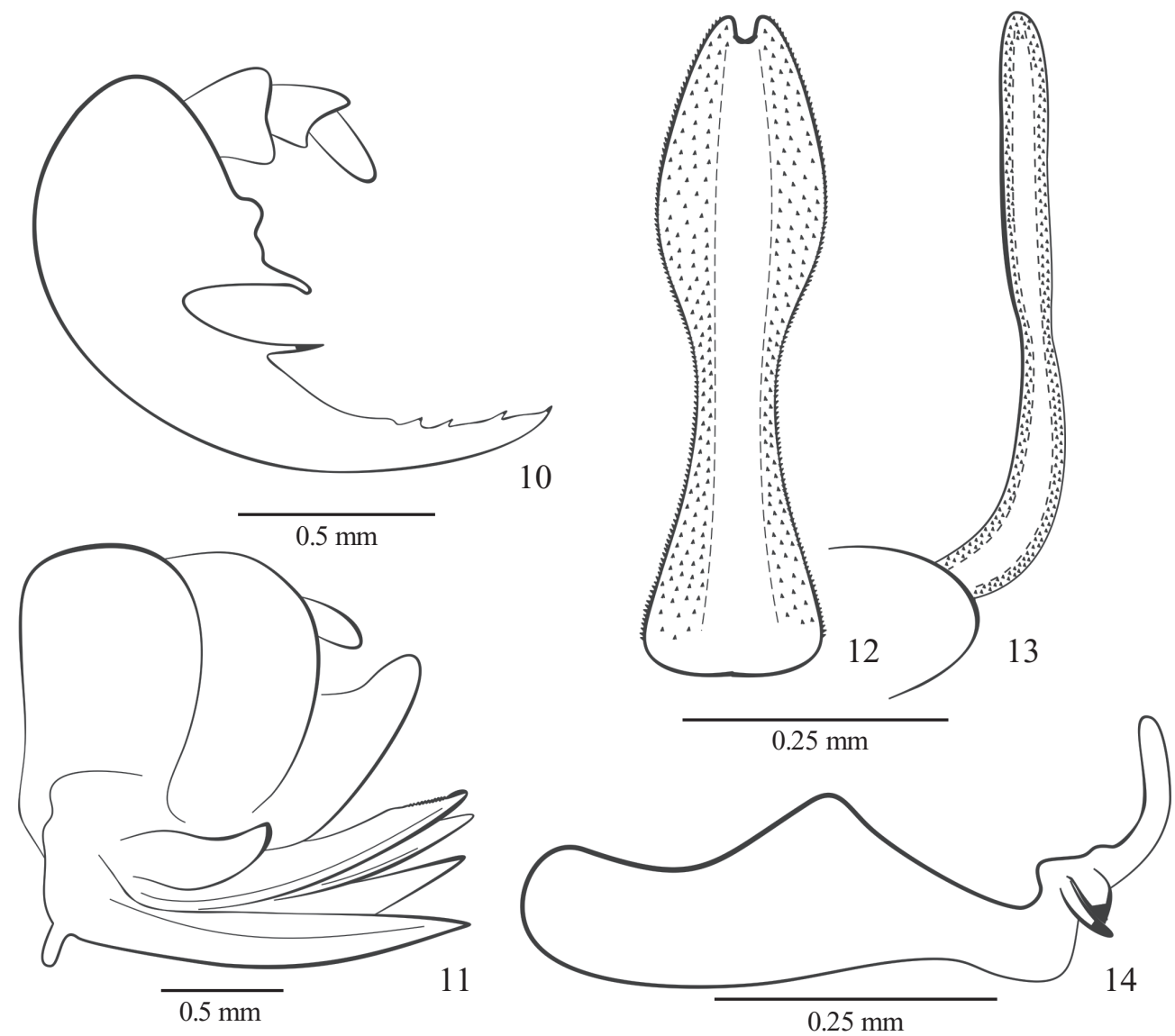

Figs. 10-14. Sphenorhina plata sp. nov. 10. Male pygofer, lateral view (MCTP-29446). 11. Female pygofer, lateral view (MCTP-29450). 12. Aedeagus dorsal view (MCTP-29446). 13. Aedeagus, lateral view (MCTP-29446). 14. Paramere, lateral view (MCTP-29446). 
thorax, mesothorax and metathorax reddish, pronotum black with anterior margin red, hexagonal without a median carina; anterior margin straight, lateral-anterior margins straight shorter than half of anterior margin, lateral posterior margin slightly sinuous, posterior margin almost straight, scutellum black with the apical portion red with some transversal grooves; tegmina black with one yellow stripe beginning at the $\mathrm{R}$ and $\mathrm{M}$ branching point and extending to apical third in direction of the costal margin; hind wing brown with brown venation, vein $\mathrm{Cu}_{1}$ not thickened at the base; legs brownish with coxae and basal portion of the femur red, metathoracic tibia with two lateral spines: the basal one smaller than those located in the apical crown of spine and the apical one larger, basitarsus with one row of apical spines covered by long setae, subungueal process present and triangular.

Male. Pygofer black with one finger-like process with a spine in the apex situated between the anal tube and the subgenital plates; subgenital plate long and slender with one finger-like process at the base on the dorsal margin, three spines in the dorsal margin near the apex and apex with a spine (Fig. 10), paramere with a long and slender apex, dorsal process developed, two sclerotized subapical spines directed downward (Fig. 14); aedeagus flattened dorso-ventrally, enlarged in the apical portion of the shaft and covered with a large number of tooth-like spines in the ventral surface, and an apical gonopore (Figs 12-13).

Female. First valve of the ovipositor long and slender with the dorsal margin smooth, basal process developed, long and turned downward; second valve of the ovipositor long and slender with teeth in the dorsal margin, third valve short and wide (Fig. 11).

Type material. Holotype male, ARGENTINA: Jujuy, National Park Calilegua. 2342'S 064 $51^{\circ}$ 'W, 15.I.2008, Gonçalves, A.C. col. (MACN). Paratypes, 4 males (1 - MCTP29446; 3 - MACN) same data as holotype, 1 female, ARGENTINA: Jujuy, National Park Calilegua $23.72613^{\circ} \mathrm{S}$ $064.85881^{\circ} \mathrm{W}, 550-1100 \mathrm{~m}$, sweep. 14-16.I.2008, D.M. Takiya leg., (MCTP-29450); 1 male and 1 female, ARGENTINA: Jujuy, National Park Calilegua $23.72613^{\circ} \mathrm{S} 064.85881^{\circ} \mathrm{W}$ 550-1100m 14-16.I.2008 D.M. Takiya leg. Sweep. (MACN); 1 male and 1 female, same data as holotype. (DZUP).

Remarks. The male genitalia of this species resemble those of S. veterana (Jacobi, 1908), S. fissurata Lallemand, 1938, and $S$. minuta Carvalho \& Webb, 2004 in having the aedeagus flattened and lacking a ventral spine, and in the structure of the parameres and the subgenital plates. The color of the tegmina and the narrow yellow stripe, however, is unique to $S$. plata.

Etymology. The species name refers to the flatness of the aedeagus.

\section{ACKNOWLEDGMENTS}

We thank the Coordenação de Aperfeiçoamento de Pessoal de Nivel Superior (CAPES) for granting fellowship to A.P. and to the Conselho Nacional de Desenvolvimento Científico e Tecnológico (CNPq) to G.S.C. (Process: 304287/2009-1). We also thank C. Dietrich (Illinois Natural History Survey) for obtaining the collecting permits in the National Park Calilegua (Jujuy, Argentina), and the two anonymous reviewers.

\section{REFERENCES}

Amyot, C.J.B. \& Serville, A. 1843. Histoire Naturelle des InsectesHémiptères. Paris, Librairie Encyclopédique de Roret, lxxvi+675 p.

Blanchard, C.E. 1848. Sphenorhina, p. 747. In: Orbigny, C.D. (ed.). Dictionnaire universel d'histoire naturelle, vol. 11. Paris, Renard, Martinet et cie, iv $+816 \mathrm{p}$.

Carvalho, G.S. \& Webb, M.D. 2005. Cercopid Spittle bugs of the New World: (Hemiptera, Auchenorrhyncha, Cercopidae). Sofia, Pensoft, $271 \mathrm{p}$.

Fennah, R.G. 1968. Revisionary notes on the New World genera of cercopid froghoppers (Homoptera: Cercopoidea). Bulletin of Entomological Research 58: 165-190.

Metcalf, Z.P. 1961. General Catalogue of the Homoptera. Fasc. VII Cercopoidea, Part 2, Cercopidae. Raleigh, North Carolina State College, $616 \mathrm{p}$. 